\title{
DE LA MEMORIA CULTURAL A LA TRANSCULTURACIÓN DE LA MEMORIA: UN RECORRIDO TEÓRICO
}

\author{
Karen Saban \\ Universität Heidelberg \\ Heidelberg, Alemania \\ karen.saban@rose.uni-heidelberg.de
}

\begin{abstract}
RESUMEN / ABSTRACT
En este artículo se propone un recorrido teórico por diferentes concepciones de la memoria, útiles para reflexionar sobre el contacto cultural: desde las teorías elaboradas en la primera mitad del siglo XX en Europa (W. Benjamin y M. Halbwachs), pasando por el "boom memorialístico" de los años 80 y 90 (P. Nora, J. y A. Assmann, A. Huyssen) hasta los conceptos de memoria cultural y memoria colectiva que incluyen un punto de vista semiótico y antropológico (A. Erll) o tienden a pensar también aspectos transnacionales y transculturales como el terrorismo, la migración, las comunicaciones virtuales y el poscolonialismo (M. Rothberg, D. Levy, A. Baer y N. Sznaider). Por último, se discute de qué manera este nuevo paradigma en los estudios de la memoria europeos podría enriquecer el análisis de fenómenos asociados a la memoria en América del Sur, como la desaparición forzada, la transmisión transgeneracional del trauma o los discursos de los derechos humanos.
\end{abstract}

PALABRAS ClAVE: memoria cultural, transculturación de la memoria, memoria mediatizada, memoria transgeneracional, trauma colectivo.

\section{FROM CULTURAL MEMORY TO MEMORY'S TRANSCULTURATION: A THEORETICAL PATH}

This article proposes a theoretical journey through some conceptions of memory to think about issues associated with cultural contact: beginning with early theories developed in the first half of the twentieth century in Europe (W. Benjamin and M. Halbwachs), passing through the "memorial boom" in the 80s and 90s (P. Nora, J. y A. Assmann, A. Huyssen) and ending with concepts of cultural memory and collective memory that include a semiotic and anthropological point of view (A. Erll) or those concerned about global phenomena such as terrorism, migration, virtual communications and post colonialism that also require thinking in a transnational and transcultural memory (M. Rothberg, D. Levy, A. Baer y N. Sznaider). 
Afterwards I discuss how this new paradigma could well enrich the analysis of phenomena such as forced disappearance, the transgenerational transmission of trauma or the discourses of human rights in South America.

KEYWORDS: cultural memory, transcultural memory, mediated memory, transgenerational memory, collective trauma.

Recepción: 18/08/2018

Aprobación: 05/02/2019

\section{MEMORIA CULTURAL, COLECTIVA O COMUNICATIVA}

El estudio de la memoria es un fenómeno interdisciplinario e internacional que desde fines del siglo XX se ha establecido con solidez en las ciencias humanas. Podría pensarse que la necesidad de sopesar la historia obedecía a un cierto espíritu de época finisecular, según el cual la proximidad de un umbral de tiempo conlleva la tendencia a confrontar el pasado inmediato con vistas a sacar conclusiones para el futuro. Si esto es cierto, no sorprende entonces que a partir de la década del noventa se produzca en Occidente un boom de la memoria en muchas ramas del conocimiento y especialmente en los estudios culturales. Si bien en Europa la primera aparición fuerte del tema había ocurrido tras el fin de la Segunda Guerra y se había mantenido al menos hasta entrados los años sesenta gracias a la publicación de testimonios de sobrevivientes del régimen nazi (Primo Levi, Jean Amery, Bruno Bettelheim); en los años noventa, cuando empezaban a morir los últimos testigos presenciales del Holocausto, esa necesidad cobraba formas más específicas. En América Latina, la institucionalización de la memoria en el campo literario y en los estudios culturales también se inicia en la década del sesenta, aunque por motivos muy diferentes. En este caso fue la Revolución cubana que generó en todo el continente una sensibilidad política que permeó a los sujetos y los discursos y promovió, en materia literaria, el surgimiento del testimonio, género que encontraría su canonización a partir de 1970 cuando Casa de las Américas decide introducir un premio al testimonio latinoamericano (Achugar 55). Desde los años ochenta, el tema de la memoria volvería a ocupar un lugar privilegiado, esta vez debido a las transformaciones históricas que experimentaron muchos países del continente después del fin de las dictaduras. Es a partir de las memorias de Rigoberta Menchú, transcriptas por Elizabeth Burgos-Debray, Me llamo Rigoberta Menchú y así me nació la conciencia (1983), que el testimonio empieza a 
ocupar el centro del debate intelectual. La controversia, basada en la doble autoría del texto entre testimoniante y entrevistadora, puso por un lado en entredicho la validez referencial del relato, mientras que, por otro, sentó las bases de un modo progresista y solidario de compromiso intelectual con las clases marginales (Oberti 484). Todos los intentos posteriores de definir las formas y funciones del género son deudores de esta primera discusión en torno al testimonio de la líder guatemalteca de origen maya quiché, a saber, la posibilidad de representar la voz de los sujetos oprimidos y la intervención del intelectual en esta operación interpretativa, el grado de fidelidad a los hechos o su manipulación a través de la escritura, su utilidad o no para probar la verdad jurídica, su relación con el trauma y la memoria social, así como su potencial político o sus limitaciones para operar en el espacio cultural y colaborar con el proyecto democrático de las sociedades.

Tanto en Europa como en América Latina, el auge de los estudios sobre memoria no sería concebible sin el aporte de tempranas teorías que se habían elaborado sobre el tema en Europa a comienzos del siglo. La crítica coincide en señalar que Walter Benjamin y Maurice Halbwachs fueron los dos primeros autores en estudiar la memoria, integrándola en el marco de una teoría moderna de la cultura (Erll 15; Kühner 213-6). Si observamos las "Tesis de filosofía de la historia" [Über den Begriff der Geschichte] del primero, esto es fácil de comprobar. Ya en 1940 Benjamin elabora allí una teoría de la memoria, mientras establece una contraposición entre la forma de concebir la historia del materialismo histórico y de la historiografía clásica. Mientras el fascismo avanza sobre Europa y la estética del filósofo se aleja del marxismo ortodoxo, en un clima de absoluto descreimiento respecto de cualquier forma de progreso para la humanidad, la memoria asume una misión de redención histórica. La primera de las funciones de la memoria para Benjamin es redimir la historia de las catástrofes que ha acarreado. Para ello sería imprescindible romper su continuum, liberar los elementos de su apariencia y reordenarlos en una nueva unidad que los transforme. Frente al proceder sistemático y aditivo de la historia, la memoria espacializa el tiempo, lo vuelve en cierto modo atemporal para que el decurso de la historia se detenga. Habría que reconocer en el tiempo que pasa a toda velocidad una instantánea - una escena- del pasado. Así retenida, como si se tratara de una imagen, se la asocia en una nueva configuración en la que el presente pueda reconocerse. De ahí que, a contrapelo de un método científico que -según la metáfora de Benjamin- enhebra en el rosario de la historia cuentas de hechos y momentos aislados, el pasado pueda, a través de la memoria, exigir 
su derecho y arrojar luz sobre los conflictos no resueltos del tiempo actual. Hacer del pasado histórico un "pasado cargado de presente" (Benjamin 261), vale decir, un tiempo pleno, es una coyuntura revolucionaria. Mientras el historiador clásico debe olvidarlo todo -incluso el presente-con el objetivo de revivir el pasado, Benjamin propone partir del instante concreto. Tal como los revolucionarios detuvieron con un tiro los relojes parisinos, Benjamin dispone una detención momentánea del tiempo. De este modo el tiempo hace un alto y permite la introducción de un cambio de ritmo, con el objetivo de que el pasado se muestre, sea reconocido y solo entonces pase lentamente al olvido.

Otra de las concepciones fundantes de la memoria de los años veinte y treinta del pasado siglo es la de mémoire collective de Halbwachs. La teoría del sociólogo francés fue la primera en dar nombre al fenómeno y estudiarlo en forma sistemática. Aunque su recepción en América Latina tuvo alto impacto, fue traducido tardíamente (al portugués en 1990 y al castellano en 2004). El concepto de "memoria colectiva" que elabora Halbwachs tiene dos dimensiones: por un lado, se refiere a la memoria autobiográfica del individuo, que adquiere forma en un horizonte sociocultural y por lo tanto desde sus inicios ya es colectiva; por otro, el concepto tiene una dimensión cultural pues actúa dentro de grupos sociales no ahora como interacción inmediata, sino a través de expresiones objetivadas e instituciones (Halbwachs, La memoria colectiva 63-90). El núcleo de la teoría de Halbwachs lo constituye el término "marcos sociales" [cadres sociaux]. Según esta idea, el ser humano es un ser social quien sin el intercambio con otros congéneres no tiene acceso ni a la lengua, ni a las costumbres, ni siquiera a la memoria individual, ya que la mayor cantidad de experiencias en la vida de un ser humano se fundan en el vínculo con otros. Pero, ante todo, los marcos sociales constituyen una metáfora que permite expresar la circulación de saberes sobre el pasado, las nociones heredadas, las tradiciones de pensamiento; en suma, son esquemas mentales que orientan la percepción y el recuerdo (Halbwachs, Los marcos sociales 317-344). Así, según Halbwachs, los seres humanos forman parte de un orden colectivo simbólico y solo dentro de ese orden pueden recordar $\mathrm{y}$ darle sentido al pasado. Esto no quiere decir que la memoria colectiva sea una instancia supraindividual, sino que ambas, memoria colectiva e individual, están estrechamente relacionadas y se condicionan mutuamente.

Heredera de estos dos estudios tempranos sobre el tema es la teoría de la "memoria cultural" de Jan y Aleida Assmann, dos de los investigadores más destacados respecto del "cambio de paradigma de las ciencias de la 
cultura" (J. Assmann, Das kulturelle Gedächtnis 12) que se produce en las décadas del 80 y 90 en Europa. Conforme a su argumentación, toda sociedad posee una cultura específica del recuerdo [Erinnerungskultur] que establece las prerrogativas sobre aquello que no debe olvidarse. El conjunto de textos, imágenes, danzas, escenificaciones, ritos y obras de arte recurrentes que cada sociedad posee constituye el acervo de la "memoria cultural" [kulturelles Gedächtnis]. A través de su cuidado, una sociedad puede transmitir conocimientos compartidos sobre el pasado, que crean en su seno una conciencia de particularidad y pertenencia (J. Assmann, Religión y memoria cultual 41-43). Para los Assmann, la memoria cultural se opone básicamente a la "memoria comunicativa" [kommunikatives Gedächtnis]. Mientras esta última transmite experiencias en el marco de la biografía de las personas y surge por interacción viva y social, la memoria cultural vincula el pasado con el presente a través de representaciones simbólicas. Cuando la memoria viva de una comunidad se mantiene oralmente luego de tres o cuatro generaciones, corre el peligro de desaparecer y se instala la necesidad de formalizar el recuerdo. El pasaje a la simbolización sería pues, para los Assmann, la única manera de asegurar la reproducción de la memoria más allá de un horizonte comunicativo directo.

La memoria así contenida en objetivaciones culturales puede recuperar en nuevos contextos aquello que se produjo en un tiempo y lugar remotos. De este modo, se caracteriza por su independencia espacial y temporal respecto de la vida cotidiana. Como las cristalizaciones culturales carecen de inmediatez, evocan siempre in absentia experiencias pasadas y relaciones perdidas que desean recuperarse. La paradójica coexistencia de presencia y ausencia que caracteriza la memoria cultural y que los autores resumen con el oxímoron "contrapresente" [kontrapräsentisch] se explica cuando observamos que aquello que ya no es actual y ha dejado de ejercer un efecto directo sobre la vida cotidiana se recuerda a menudo con más intensidad, reintegrándose a nuestra realidad de manera simbólica. Si bien los Assmann piensan en las grandes civilizaciones de la Antigüedad (el antiguo Israel, Grecia y Egipto) y no en las sociedades contemporáneas o iletradas al elaborar su teoría, no es casual que su definición de memoria cultural haya tenido una profusa recepción en el contexto sociopolítico y cultural alemán tras la caída del Muro de Berlín, cuando el debate sobre el Holocausto se volvía a instalar en la sociedad reunificada. La recepción de esta teoría en América Latina, en cambio, tiene más corta data: llegó en forma asistemática y se produjo de modo más completo en Argentina recién en 2008, con la traducción del libro de Jan Assmann, Religión y memoria 
cultural, en un contexto en el que los debates públicos posdictatoriales sobre los derechos humanos habían empezado a formar parte de la agenda política y existía un clima receptivo para su difusión.

Recientemente los conceptos de memoria cultural y memoria colectiva han sido ampliados por Astrid Erll, quien incluye en su definición "todos los procesos orgánicos, mediáticos, institucionales en los que la interrelación y mutua influencia entre pasado y presente desempeñan un papel en el contexto sociocultural" (Erll 6). Así, la memoria colectiva no sería ni lo otro de la historia, como para Halbwachs, ni lo otro de las memorias individuales, sino más bien el contexto en el cual tienen lugar los diferentes fenómenos culturales y esto, en sentido abarcador, desde las redes neuronales hasta el estudio de las tradiciones (Erll 115). Aun más, se trataría de un modelo que concibe el carácter pluridimensional, creativo y procesual de la memoria. Esta definición posmoderna de la memoria está también en la base de lo que el grupo de investigación de la Universidad de Gießen (1997-2008) elaboró como "culturas de la memoria" [Erinnerungskulturen], una pluralidad que comprende la cultura desde un punto de vista semiótico y antropológico y permite abarcar fenómenos heterogéneos de memoria colectiva en distintas partes del mundo. El interés actual que se observa por fenómenos como la transculturación, el mundialismo y el cosmopolitismo tiene también como trasfondo esta concepción de la memoria. El concepto de memoria colectiva, así entendido, agrega por último a la teoría de los Assmann -centrada en el estatismo y la homogeneidad de las culturas letradas-, también el análisis de fenómenos de cultura popular o de prácticas de memoria cotidianas o contemporáneas, signadas por los movimientos migratorios, las minorías étnicas y los procesos mediáticos (Erll 37).

Otra teoría correctiva o complementaria es la de "memoria social" de Harald Welzer. Mientras que los Assmann habían desarrollado profusamente el concepto de memoria cultural, el de memoria comunicativa había quedado relegado como un mero polo opuesto, y como tal, había sido vago en su definición y menos maleable en su aplicabilidad (Kühner 210). Basándose en la Oral History, Welzer busca su objeto de estudio justamente en la memoria comunicativa y se propone precisar el concepto tanto teórica como empíricamente. Ante todo, le interesa estudiar las formas de la memoria que surgen de la interacción concreta entre las personas, por eso propone trabajar con lo que llama prácticas sociales de memoria. Para contrarrestar la dificultad que significa el estudio de la memoria colectiva en su desarrollo natural y vital, Welzer desarrolla el método de la transmisión de la conciencia histórica, con 
el cual analiza la socialización y la psicología que subyacen a las prácticas de memoria entre generaciones. Una de sus características, confirma, es la involuntariedad que hace que muchas de las memorias colectivas se construyan según el principio que alienta el juego del teléfono descompuesto; es decir, la memoria se va deformando a través de las generaciones de modo tal que el abuelo nazi se transforma, en la memoria del bisnieto, en un héroe de guerra nacional (Welzer et al., "Opa war kein Nazi" 54). En Mi abuelo no era nazi, Welzer y su equipo analizan de esta manera múltiples narraciones familiares alemanas que tienen la función de alivianar la culpa y crear mitos positivos en el seno de la comunidad.

Aleida Assmann, por su parte, extiende y especifica la teoría de la memoria cultural en su libro Erinnerungsräume (1999), donde distingue entre memoria como arte $[$ ars $]$ y memoria como fuerza $[v i s]$. La primera forma de pensar la memoria es la que da origen a la mnemotécnica antigua. En De oratore, Cicerón había llamado la atención acerca de la cualidad sugestiva que existía entre los lugares históricos [loci] y las imágenes mentales creadas a partir de ellos [imagines] en tanto bloques de construcción de la memoria. Si los lugares podían afectar las emociones a través del sentido de la vista, entonces era justamente mediante la reconstrucción mental de saberes asociados a lugares que se podía memorizar informaciones a largo plazo. Según Cicerón, la leyenda fundacional de la mnemotecnia es la del poeta griego Simónides de Ceos (550-460 a.C.), quien, invitado al banquete de un noble para recitar un poema laudatorio, fue testigo del derrumbe de la casa y de la muerte de los comensales. Como único sobreviviente, pudo reconocer los cuerpos destrozados recordando los lugares donde estaban sentados y así permitir que sus familias les dieran sepultura. Aquello que el poeta griego había inventado sin saberlo es la técnica que Cicerón desarrolla conscientemente con el fin de memorizar textos y discursos, codificando sus partes y asociándolas a un mapa mental para recitarlas de memoria. También Renate Lachmann, en Gedächtnis und Literatur, se refiere a la parábola de Simónides de Ceos, pero no para argumentar como Cicerón que las imágenes mentales son miméticas respecto de los acontecimientos, sino apoyándose en la interpretación que hace Quintiliano, para demostrar la calidad mediadora y transformadora de la memoria, que es siempre un acto de interpretación que necesariamente selecciona y transforma los hechos al ordenarlos en un relato, en la representación discursiva de un acontecimiento. Así, la anécdota no ejemplificaría otra cosa que la inextricable relación entre memoria y literatura (Lachman 21-23). 
Para Aleida Assmann, el cambio de paradigma entre memoria como ars y memoria como vis se produce a más tardar a fines del siglo diecinueve, cuando se abandona la idea de que la memoria es una técnica para reactivar un archivo de informaciones claramente localizadas y se la pasa a considerar una fuerza procesual y activa. La primacía de un modelo topológico o temporal de la memoria es, para la especialista en estudios literarios y culturales, un indicador de tendencias políticas y estéticas específicas. Como las formas privilegiadas de practicar la memoria cambian con las épocas, el conflicto esencial entre la memoria individual y la memoria colectiva -recuérdese que ésta última tiene que poder existir independientemente de la experiencia personal para fundar tradiciones y prácticas culturales a futuro-se renueva una y otra vez a lo largo del tiempo sin llegar a resolverse nunca. Para comprender mejor este problema, Aleida Assmann establece una nueva diferenciación en la teoría de la memoria cultural. Con los modos complementarios de la "memoria de almacenamiento" [Speichergedächtnis] y la "memoria funcional" [Funktionsgedächtnis], puede distinguir, a su vez, entre los procesos de olvido o activación del recuerdo (A. Assmann, Erinnerungsräume 133-142). La memoria de almacenamiento sería aquella "inservible, obsoleta y que ha devenido extraña" (137). La memoria funcional, en cambio, es la memoria "habitada", que ha seleccionado ya los elementos cargados de sentido y que están en condiciones de ser configurados en una historia coherente en función de los valores del grupo. Para la investigadora alemana, ambas formas no se autoexcluyen, sino que coexisten. Su relación tiene que ver con la perspectiva desde la que se las observe. La memoria funcional se destaca en un primer plano sobre la memoria de almacenamiento, que se mantiene desactivada y a la espera. En tanto "repertorio de posibilidades desperdiciadas, opciones alternativas y chances no utilizadas" (137), la memoria almacenada puede ser esencial para la trasformación cultural de una sociedad. Todos esos elementos olvidados pueden, en un contexto espacio-temporal diferente, pasar a formar parte de la memoria funcional y así garantizar la actividad de la memoria cultural. De este modo, la autora extiende el concepto original de memoria cultural (que parecería solo incluir la memoria funcional) e incluye también documentos archivados y olvidados, obras de arte que perdieron importancia, construcciones arquitectónicas ignoradas, en suma, todos aquellos elementos del pasado latentes y potencialmente útiles que podrían llegar a ser reactualizados. 


\section{DE LOS LUGARES DE MEMORIA NACIONAL A LA MEMORIA GLOBAL Y MEDIATIZADA}

Por otro lado, la discusión en torno al giro cultural de la memoria frecuentó caminos completamente opuestos, tendientes a adscribir el fenómeno en la era de las comunicaciones virtuales, la globalización y la mercantilización de los bienes culturales. Andreas Huyssen, una de las voces más citadas en las discusiones teóricas sobre memoria, sitúa el estallido del tema menos en razones de índole teleológica-como el matrimonio Assmann- que tecnológica. Mientras el futuro y el valor de lo nuevo eran el horizonte que habían alentado a lo largo y a lo ancho del siglo veinte a la cultura, al menos hasta las neovanguardias de las décadas de 1960 y 1970, llegada la década de 1990, la modernidad -en un gesto de escepticismo y desesperanza- daría un vuelco hacia el pasado y lo conocido (Huyssen, Present pasts 11). Pero esta propensión no se desarrolla solo como consecuencia de las utopías en crisis, sino también como reacción al vértigo que produce la aceleración del tiempo en un mundo altamente mediatizado, computarizado y transnacionalizado. Huyssen constata que los tiempos modernos, en especial mediante la introducción de los medios de comunicación, sufren un aumento de velocidad. Si toda la información pasada y presente puede obtenerse gracias a Internet, el conocimiento parecería no tener límites. También la posibilidad de archivar datos se ha extendido hasta lo inimaginable y paradójicamente trae consigo el peligro del olvido. En efecto, la selección y la apropiación de lo que habría que recordar es cada vez más difícil. Asimismo, los intervalos de tiempo se acortan hasta que todo pasa a ser parte de un presente ubicuo. El vuelco hacia la memoria podría vincularse con el deseo de volver a introducir en la experiencia de vida estructuras de tiempo más extensas (Huyssen, Twillight memories 5-7). La teoría de Huyssen dio pie al desarrollo de una nueva rama de investigación dentro de los estudios de memoria, dedicada a analizar la influencia de los medios masivos de comunicación y de las nuevas tecnologías digitales en la formación de la memoria social, tanto comunicativa como cultural.

Otra teoría de la memoria constitutiva de la cultura actual que cobra importancia en los años ochenta y noventa en Europa y que tiene gran recepción en América Latina es la de los lugares de memoria [lieux de mémoire] de Pierre Nora. Los siete tomos de Les lieux de mémoire (1984-1992), una obra realizada por diferentes especialistas bajo la dirección del historiador francés, constituyen una de las historiografías más importantes de Europa. Mientras Huyssen concibe la memoria en la actualidad como un campo de estudios 
necesariamente ligado a la globalización, Nora construye un concepto en cierto modo conservador, ligado todavía a la memoria nacional. También a diferencia de los Assmann, que confían en el potencial de la memoria cultural, para Nora lo que queda como sustituto de su inexistencia son lugares de memoria, que él considera residuos, remanentes, restos, fragmentos o huellas de un pasado que ya no existe y que está irremediablemente perdido. Para Nora éstos pueden ser ciudades enteras, memoriales, monumentos, obras de arte, personalidades históricas, fechas, textos científicos o filosóficos, acontecimientos simbólicos, etc. Así, los lugares no hacen sino mostrar la distancia que los separa de lo que fueron y son solo difusos intermediarios de un pasado que no cesa de desvanecerse. "Se habla tanto de memoria porque ya no hay memoria" (19), escribe Nora. No hay ya, según él, ninguna relación con un pasado que dispensaba identidad y pertenencia.

\section{MEMORIA Y OLVIDO, DOS PARES COMPLEMENTARIOS}

Entre los estudios sobre memoria no faltan las reflexiones sobre las formas del olvido, su par complementario, pero no ya como en Nora, entendido como la polaridad negativa de la memoria, sino para mitigar los riesgos asociados al exceso de la memoria histórica, especialmente cuando se trata de superar acontecimientos catastróficos del pasado. Así, muchos autores se manifiestan en favor de limitar la memoria a unos cuantos usos específicos para evitar el cisma y la venganza en las sociedades traumatizadas y sugieren introducir, en ciertas dosis, el olvido como praxis. En Formen des Vergessens (2016) Aleida Assmann señala que, a diferencia de la corriente afirmación que menosprecia el olvido por natural y espontáneo y atribuye a la memoria exclusivamente ser resultado de un esfuerzo consciente por parte de los seres humanos, el olvido es no solo un proceso activo sino incluso imprescindible para la memoria (711). En su estudio distingue entre técnicas como la selección, la focalización, los mecanismos de defensa de los victimarios o el olvido constructivo de los nuevos comienzos y vincula todas esas formas del olvido a ejemplos tan diversos como la invisibilidad de los monumentos, el olvido de los crímenes de lesa humanidad a la sombra del Holocausto o la imposibilidad del olvido en Internet para demostrar que olvido y memoria son inseparables.

Sin embargo, la idea del olvido productivo no es nueva sino que data de antiguo. Ya en Vom Nutzen und Nachteil der Historie für das Leben (1874), donde discute con el historicismo de su época, Nietzsche había descrito tres 
maneras diferentes de relacionarse con la historia: monumental, anticuaria y crítica. Las dos primeras las relaciona con un abuso de memoria, mientras que solo la última es la manera legítima de recordar el pasado, ante todo porque incluye la posibilidad del olvido. La "historia monumental" implicaría encontrar en los triunfos pasados un ejemplo para el presente. Se trata de una memoria optimista que desconoce la resignación y promueve la imitación y el mejoramiento del modelo conocido. Sin embargo, en este himno al pasado, los hechos corren el peligro de distorsionarse, embellecerse y transformarse en un mito. El segundo modo de recordar el pasado se plasma, según Nietzsche, en la "historia anticuaria". El anticuario venera el pasado porque encuentra en él la justificación de su existencia en el presente y la ligazón con los orígenes que le otorgan identidad y pertenencia a una comunidad. Pero Nietzsche advierte que este tipo de memoria desemboca en una furia coleccionista basada en la acumulación de datos muertos, sin relación con el presente vivo. A diferencia de esos modos de la memoria, "preciosa superfluidad del conocimiento" (209), la "historia crítica" está orgánicamente unida al presente y por tanto es capaz de conformar la identidad de un grupo social. En virtud de ello, la memoria crítica tiene la capacidad de disolver de tanto en tanto, y al servicio del presente, parte de lo que fue, sometiéndolo a un interrogatorio. Se trata de la vida que juzga al pasado, y el elemento esencial de este tipo de memoria es el olvido. Pues sucede que bien puede haber existencia sin recuerdo, pero de ningún modo existencia sin olvido. Para que el pasado no sepulte al presente bajo su peso es imprescindible la "fuerza plástica" [plastische Kraft] del olvido (213) que permite discernir entre los momentos de la vida en los que es necesario sentir en forma histórica (o sea, con plena conciencia del pasado) y aquellos en los que es más saludable sentir en forma ahistórica (y en los que predomina, en consecuencia, la acción con vistas al futuro).

Entre los autores que retomaron mucho después la idea nietzscheana de la memoria "hipertrófica" y paralizadora de la cultura y la vida, por un lado, y el olvido como parte de una memoria consciente y deliberada por otro, se cuenta Tzvetan Todorov, quien descartó el imperativo de la memoria, que pretende sacralizar el pasado mediante su recuperación "literal", para privilegiar en cambio una memoria "ejemplar", subordinada al presente, que selecciona del pasado solo aquellas escenas de injusticia que pueden resultar edificantes para luchar contra las que se siguen cometiendo en la actualidad; es decir, que sin negar los hechos singulares, pueda usarse como modelo para comprender situaciones nuevas y semejantes. Según este autor, la memoria ejemplar conlleva la ventaja de que neutraliza el dolor causado 
por el recuerdo y lo abre a la analogía para sacar un ejemplo "con vistas al presente, aprovechar las lecciones de las injusticias sufridas para luchar contra las que se producen hoy día, y separarse del yo para ir hacia el otro" (Todorov 31). A la inversa, el peligro asociado a la "memoria literal" es que quede diluida en comparaciones universales y que los hechos referidos pierdan su identidad. La memoria literal, en su visión excesiva, conserva el suceso traumático sin poder conducirlo más allá de sí mismo y extiende las consecuencias del sufrimiento a todos los instantes de la existencia, desencadenando solamente venganza.

Paul Ricoeur, por su parte, distingue entre tres formas de olvido que actúan no como el polo opuesto de la memoria, sino entre dos planos diferentes de memoria, a saber, la memoria profunda, como inscripción o conservación, y la memoria manifiesta, relacionada con la evocación y la rememoración. En el pasaje de uno a otro plano, el olvido puede ser pasivo, evasivo o activo. Mientras que el primer tipo de olvido coincide con el trauma, es involuntario e inconsciente, el segundo tipo se vincula con la represión, es decir, es una estrategia de negligencia u omisión. El último tipo de olvido, en cambio, sería el modo selectivo e interpretativo de los recuerdos (Ricoeur 53-62). Todos estos autores intuyeron que la memoria, concebida como reservorio total y exterior, no hace más que engendrar hostilidad y violencia o, en el mejor de los escenarios posibles, quitar el peso de la responsabilidad moral a los ciudadanos. En una acertada metáfora, Gerard Wajcman escribe que los monumentos y otros sitios de memoria son como serenos que patrullan las calles y velan por los buenos sueños de los ciudadanos. Así, la memoria, archivada en forma externa, quita el deber de memoria a los seres humanos que, paradójicamente, pueden olvidar aliviados (Wajcman 232). El olvido administrado en dosis prudentes podía resultar liberador o creativo, según propuso también Harald Weinrich en su ensayo Gibt es eine Kunst des Vergessens? (1996). Estimulado por una conferencia de Umberto Eco de 1966 en la cual el semiótico italiano argumenta que no puede existir un ars oblivionalis, puesto que los signos manifiestan siempre la presencia y no la ausencia de algo (Eco 254-261), el autor alemán comprueba lo contrario. Apoyándose en ejemplos tanto literarios como documentales, y sobre todo en la teoría freudiana, devela las astucias del olvido. En este sentido, la terapia psicoanalítica no sería sino un largo camino que conduce, mediante la ardua narrativa de la memoria, de un olvido aplacador dado por la represión que opera en el inconsciente a un olvido que terminará por pacificar al sujeto al llevarlo a la consciencia (Weinrich 35-45). 
Estos pensadores, desde tiempos y contextos diferentes, alegaron en favor de un uso parcial del olvido o un uso crítico, activo y afectivo del recuerdo bajo ciertas circunstancias, con fines determinados y mediante estrategias precisas. En suma, el olvido había sido considerado hasta ahora como un estado de excepción o como un componente necesario y productivo dentro del proceso de memoria. Por el contrario, en su libro Das Gebot des Vergessens (2010), el historiador alemán Christian Meier eleva el olvido al estatuto de modelo de salvación para las sociedades torturadas por su pasado. Llama la atención esta tesis en un contexto que se debate desde hace más de 70 años por saldar cuentas con los crímenes del Holocausto, así como en un tiempo de giro en la historia del pensamiento en que prima el paradigma de la memoria (Saban, reseña 99-103). Sin embargo, el ensayo de Meier puede estar captando un espíritu de pesimismo cultural paralelo y muy actual que también se encuentra en otros pensadores alemanes, quienes de un tiempo a esta parte ponen en duda que la escenificación de la memoria del Holocausto en Alemania redunde en algún beneficio y explican que cuando la memoria ya ocupa el discurso paradigmático en el espacio público, los planes de estudio y los medios de comunicación, hablar de memoria solo puede producir hartazgo y rechazo (Welzer y Giesecke 7-26; Jureit y Schneider 7-16); con ellos discute sin embargo Aleida Assmann en Das neue Unbehagen an der Erinnerungskultur (2013) cuando establece una distinción entre una memoria vinculada al "saber cognitivo" [kognitives Wissen] hecho de datos, fechas e informaciones que llevado al paroxismo puede ser contraproducente, y una muy diferente y más difícil de cultivar para el pueblo alemán, vinculada al "saber afectivo", es decir, al conocimiento que se adquiere al poner los hechos en relación con la propia identidad [Wissen mit Identitätsbezug] (71-72).

Meier parte de la certeza de que la memoria histórica sería un fenómeno tardío, inaugurado unos veinte años después del fin de la Segunda Guerra Mundial, pero sin suficientes pruebas de eficacia en la historia de la humanidad concebida en sentido amplio. Según su hipótesis, la memoria puede haber sido el camino correcto para enfrentar el pasado nazi, pero es inconveniente cuando se lo intenta aplicar a otros traumas históricos (Meier 94-143). Como versado historiador cita una serie de casos empíricos que refutan el modelo de la memoria y, con él, su utilidad para el crecimiento democrático de las sociedades. Cientos de indultos y tratados de paz a lo largo de la historia mundial son para él prueba de que el olvido habría sido el modo de regular la vida con posterioridad a guerras, guerras civiles y traumas históricos. La tesis de Meier tiene una consecuencia, por lo menos, polémica. Aplicado a las 
generaciones venideras, el mandamiento del olvido se refiere necesariamente a la ruptura en la transmisión de los acontecimientos históricos. Solo puede olvidarse lo que se ha experimentado o recibido, de modo que el mandamiento del olvido no afecta solo a los hechos pasados, sino que sería en última instancia la orden de suspender el conocimiento del pasado en el presente $\mathrm{y}$ en el futuro.

\section{LA MEMORIA TRANSNACIONAL Y TRANSCULTURAL}

En oposición a una concepción de la memoria nacional de la que todavía se hacía portavoz Nora, los estudios más actuales sobre el tema, preocupados por fenómenos globales como el terrorismo, la migración, las comunicaciones virtuales y el poscolonialismo, requieren pensar en una memoria transnacional y multidireccional (M. Rothberg) y han, de hecho, empezado a modificar la tendencia en los estudios de memoria (Erll 58). Esto es cierto, sobre todo, para Europa y EE.UU.; para el mundo hispanoamericano, en cambio, la recepción de las teorías de memoria transcultural en los estudios de memoria está todavía en sus inicios (p. ej., Lie y Mahlke 543-545, Mandolessi y Alonso 9-20, Hansen 123-151, Cruz Suárez 183-222).

A partir del ataque suicida a las Torres Gemelas en Nueva York, se empezó a hablar de una "globalización del terrorismo". Paralelamente, el hecho representó un nuevo giro en el paradigma de la memoria, que ahora revelaba su carácter transcultural y transnacional. Así, por ejemplo, el ataque al centro neurálgico del capitalismo mundial fue el prisma según el cual se trataría de poner nombre a otros sucesos que se vivían como igualmente traumáticos. Piénsese en la abreviación " $11-\mathrm{S}$ " con que se aludió a la fecha del crimen y que se repetiría en otros casos, por ejemplo, en el 11-M (de los atentados de Madrid) o en el 22-M (de los atentados de Bruselas), que aludían así a las dimensiones globales del trauma.

Uno de los primeros trabajos que señala esta tendencia es el libro de Levy y Sznaider Holocaust and memory in the global age (2006). Los autores acuñan allí el concepto de "memoria cosmopolita" (23) para referirse al Holocausto como el sitio paradigmático de la globalización del recuerdo, ya que se ha convertido en el punto de referencia para otras prácticas de memoria connotadas negativamente a lo largo y ancho del mundo. Con la voluntad de hacerse visibles y reclamar reconocimiento, diferentes grupos de víctimas, desde el "Holocausto negro" (114) hasta el "Holocausto de Kosovo" (166), 
suelen recurrir al Holocausto judío como analogía. Según los autores, se trata de una dinámica de descontextualización y recontextualización de la memoria. Pero el uso del Holocausto como metáfora acarreó sin embargo fuertes críticas. Andreas Huyssen señaló que la utilización del Holocausto como universalización del mal es un arma de doble filo: si por un lado las comparaciones pueden sensibilizar a un grupo mayor de personas e incentivar la reflexión acerca de la existencia de un imaginario global de catástrofes, de igual forma pueden desatar analogías de tenor insustancial y cotidiano. Esto llevaría a que se releguen y simplifiquen temas incómodos y difíciles de clasificar, como sucede con los a veces excesivos usos del Holocausto (Huyssen, Twilight Memories 5-7). De este modo, advierte que el ímpetu por recordar acontecimientos "crepusculares" de la historia a través del "prisma" del Holocausto puede muy bien surgir del deseo opuesto de oscurecer tanto el punto de referencia como los desastres por él interpretados. Por ejemplo, al comparar a los victimarios del presente con los nazis, fácilmente pueden invertirse los términos y los perpetradores ponerse en escena como inocentes. Los paralelismos pueden también simplificar demasiado la práctica de la memoria y transformar los acontecimientos traumáticos en lugares vacíos de significado, como sucede a menudo en la industria del entretenimiento (Huyssen, Present Past 13-14).

En Multidirectional memory (2009), Michael Rothberg también se pregunta sobre la relación entre el Holocausto, la memoria y la transnacionalidad. Usando un concepto proveniente de las redes mediáticas y digitales, el autor parte de la hipótesis de que la memoria cultural opera en función de la dinámica multidireccional, esto es, un discurso sobre el pasado antes que excluir otro discurso, lo posibilita. La memoria opera a través de la "negociación, las referencias cruzadas y el préstamo" (15) y no sobre la base de la competencia y la oposición de los diferentes traumas. La globalización de la memoria del Holocausto no desplaza o silencia otras memorias traumáticas, sino que, al contrario, puede servir para enfatizarlas o interpretarlas. A diferencia de Huyssen, Rothberg sostiene que el concepto de "recuerdos encubridores" de Freud se relaciona estrechamente con el de memoria multidireccional, ya que a la vez esconde que puede revelar lo reprimido. La memoria multidireccional no reemplaza una memoria reconfortante por otra, sino que yuxtapone dos que son inquietantes por igual (13).

La memoria tiene entonces un componente ético en la medida en que puede apuntar a la solidaridad y al mutuo reconocimiento entre víctimas. Erll tiene en mente el concepto acuñado por Rothberg cuando escribe que la 
transculturalidad de la memoria no es solo una categoría para analizar prácticas de memoria actuales y posmodernas. Más bien se trata de una perspectiva sobre fenómenos de memoria colectiva, y por tanto puede ser utilizada para analizar la lógica de la memoria cultural en épocas históricas tanto prenacionales, nacionales como posnacionales. En este sentido crea, a partir de la teoría de la diáspora de Clifford (302-338), el concepto de "travelling memory" (Erll 125) para señalar que la memoria está en constante movimiento junto con los seres humanos y sus medios de expresión. Muchos de los fenómenos que estaríamos dispuestos a considerar propios de la memoria cultural, estables y particulares de un grupo social determinado son en realidad transculturales desde su mismísimo origen. Para Erll, la memoria viaja en cinco formas diferentes: con las personas (que llevan consigo en sus diásporas los mitos familiares y sus culturas de origen), con los medios (libros u otros objetos portables), con las imágenes (esculturas, cuadros, fotografías), a través de contenidos (esquemas, íconos, narraciones, símbolos) y por último a través de prácticas (costumbres, rituales). Esta memoria móvil puede empezar a identificarse, aunque todavía en forma incipiente, también en procesos de memoria hacia y desde el continente latinoamericano.

Entre las teorías innovadoras que se han escrito en los últimos años en América Latina se destaca el trabajo de Daniel Feierstein quien, legitimado por el uso que le dio en el espacio jurídico el juez español Baltazar Garzón, importa del contexto europeo el término "genocidio", originalmente usado para referir los crímenes del nazismo entre 1933 y 1945, y lo introduce en la Argentina, cambiando el objeto de referencia, con el propósito de analizar los crímenes de la última dictadura militar. El pasaje del término y su inserción en un nuevo ámbito de estudio no se producen sin atención a la especificidad de su contexto de origen, pero al acuñar la expresión "práctica social genocida", el autor lo adapta a otra realidad. En su definición, el genocidio moderno no solo se limita al "aniquilamiento sistemático de grupos sociales" (Feierstein 35-36), ya sean étnicos, nacionales, raciales o religiosos, sino que constituye una tecnología de poder destructora también a nivel social y simbólico, sobre todo abocada a la eliminación de ciudadanos del propio país; un caso comparable a los de Camboya o Indonesia.

Pero la memoria no viaja solo de Europa a América Latina, sino que toma a menudo también la ruta inversa. Por ejemplo, hay autores que señalan cómo la figura del "desaparecido", acuñada en el contexto posdictatorial de los países de América del Sur y especialmente en Argentina como "desaparición forzada" gracias a la fuerza emocional que le imprimieron los familiares de 
las víctimas unidos en organizaciones como Madres y Abuelas de Plaza de Mayo, pasó a usarse recientemente en el debate por la memoria en España, en reemplazo del eufemismo de "fusilados y paseados" que usaba el régimen de Franco (Mandolessi y Perez 605). Siguiendo a Rothberg, podría decirse que el traspaso de un término de larga tradición en la lucha por los derechos humanos en el Cono Sur a un contexto nuevo tiene la virtud de hacer visibles en el debate social español crímenes que habían sido largamente olvidados u ocultados durante el régimen franquista y también durante la transición democrática, a la vez que se revela que dichos crímenes fueron violaciones a los derechos humanos. El desarrollo transnacional de la memoria entre España y Argentina no es nuevo; de hecho, ya se había producido antes, aunque en términos inversos, cuando durante la década de 1990 los juicios a los genocidas de los regímenes militares integrados en la Operación Cóndor no ocurrían en territorios locales -por entonces todavía reactivos a hacer memoria-, sino que tenían lugar gracias al juez Garzón en España y eran, en territorio ajeno, la única realidad posible para la justicia local. De nuevo al revés, cuando Garzón intentó llevar a juicio en 2010 las atrocidades del franquismo, fue suspendido de sus funciones y, en cambio, fue una corte argentina quien se hizo cargo de encabezar las querellas por los casos de los desaparecidos españoles en fosas comunes.

Otro ejemplo de memorias en movimiento a través de distintos países de América Latina es la agrupación H.I.J.O.S. (Hijos e Hijas por la Identidad y la Justicia contra el Olvido y el Silencio), activa en Argentina desde 1996, que fue desembarcando con el correr de los últimos veinte años en México, Colombia, Guatemala, Uruguay, Nicaragua y Chile. También las comisiones de la verdad en el continente son un buen ejemplo de multidireccionalidad de la memoria. La primera de ellas, CONADEP (Comisión Nacional sobre la Desaparición de Personas), fue convocada en 1983 por Raúl Alfonsín, el primer presidente argentino tras el fin de la dictadura. Las denuncias y pruebas recibidas fueron compiladas en el informe Nunca Más (una fórmula de por sí multidireccional, puesto que habría sido acuñada por los judíos liberados de los campos y escrita en el gueto de Varsovia durante su levantamiento en 1943) y sirvieron como base para los juicios que se celebraron dos años más tarde. La de Chile, también decretada tras el fin de la dictadura (1990), retomó la experiencia argentina, aunque prohibió expresarse sobre las responsabilidades. Aunque las de El Salvador (1991) y Guatemala (1996) tuvieron lugar en condiciones diferentes, utilizaron también como trasfondo las experiencias de sus vecinos sudamericanos. Incluso el lema "Nunca Más" pasó a formar 
parte de la recuperación de la memoria histórica de muchos otros países: "Guatemala Nunca más", "Brasil Nunca más", "Uruguay Nunca más". Por último, Baer y Sznaider (1-27) también rastrean el cosmopolitismo del término "Nunca Más" en Europa y su inserción, desde su origen argentino, para dar cuenta, por ejemplo, de la experiencia española. La exhumación de las fosas comunes de Franco y el vuelco hacia la memoria en España tras décadas de silencio fueron analizadas con pormenores en el libro de Francisco Ferrandíz El pasado bajo tierra (2014), libro en el cual también se hace referencia al "Nunca Más Guerra Civil".

\section{MEMORIA TRANSGENERACIONAL Y POSMEMORIA}

Otro concepto de actualidad en los estudios de memoria, que tuvo más recepción que las teorías de transculturación en el estudio de los procesos de memoria y sus expresiones en el ámbito hispanoamericano, es el de posmemoria [postmemory], elaborado por Marianne Hirsch. Se trata de una categoría narratológica que le sirve a la autora para analizar la herencia transgeneracional de la memoria y el trauma en hijos de sobrevivientes del Holocausto. Según la tesis expuesta en trabajos como Family frames. Photography, Narrative, and Posmemory (1997) y The generation of Postmemory: Writing and visual culture after The Holocaust (2012), las fotografías y los relatos que circulan en las familias, pero también los modos de vinculación y tratamiento entre generaciones, pueden conectar poderosamente a abuelos, hijos y nietos a través del tiempo. Aun tratándose de memorias de segunda mano, los recuerdos de los antecesores les son transmitidos a los descendientes con tanta carga emocional que tienen el valor de recuerdos propiamente dichos. Sin embargo, como la conexión con el pasado se produce en forma indirecta, "Postmemory's connection to the past is thus not actually mediated by recall but by imaginative investment, projection, and creation" (Hirsch, The generation of Postmemory 107). Según esta noción, el pasado también puede constituir una carga opresiva para los hijos y aún los nietos de las víctimas, quienes se sienten tan comprometidos con el pasado de los progenitores que corren el peligro de relegar su propia vida en favor de la de aquellos. Esta suerte de prolongación de la experiencia hace que sea posible hablar de memoria heredada o "posmemoria". Su correlato en las teorías psicoanalíticas contemporáneas de Alemania, que reflexionan sobre los efectos a largo plazo del Holocausto, sería el concepto de "transmisión transgeneracional del trauma" (Straub y Grünberg 7-38 y 
Hardtmann 39-56). Según esta concepción, el trauma ya no tendría, como en la teoría freudiana, el carácter de un shock, sino que sería procesual y acumulativo. Así, las vivencias dolorosas excederían al sujeto sufriente y se heredarían a través de las prácticas sociales, continuando al menos hasta la segunda y acaso la tercera generación.

El término tuvo una positiva recepción entre investigadores del Holocausto como James Young, quien analiza en At memory's Edge (2000) la producción artística y arquitectónica de las generaciones post-Holocausto. Partiendo de la teoría de Hirsch, habla de "memorias vicarias" para plantear que la memoria de quienes no vivieron los acontecimientos es esencialmente diferente al discurso del testimonio, no solo indirecta sino también hipermediada, y experimenta con materiales estéticos que rechazan la representación y el carácter redentor del arte. Así, en su análisis de los memoriales del Holocausto, Young se refiere al potencial crítico de lo que llama "contramonumentos", artefactos que cuestionan la posibilidad de representar el pasado y acentúan su carácter incompleto y efímero. Estos proyectos arquitectónicos apuntan ya no a convertirse en los "lugares de memoria" como a los que se refería Nora, sino a transformar las disidencias políticas y las controversias éticas -que a menudo acarrean- en parte del acontecimiento estético. Es más, acaso la irresolución de esas propuestas sea fundamental porque garantiza la visibilidad y continuidad del proceso de memoria (Young 92).

La posmemoria sería entonces una forma especialmente subjetiva, íntima, afectiva, y virulenta del recuerdo, a pesar de la distancia temporal y de la mediación con la que se construye. La razón radica en que los protagonistas de las nuevas generaciones están menos interesados en un acontecimiento histórico en sí que en los efectos y la influencia de la experiencia traumática en sus vidas. Por ello también pueden encontrarse muchos ejemplos, entre la producción artística y literaria de los hijos de desaparecidos en América Latina, que manifiestan estrategias de hipermediación e intermedialidad, por medio de las cuales eligen relatar y representar los procesos de memoria y guardar así distancia o incluso parodiar (Gatti 147-151) los relatos referenciales o documentales del pasado. Así, por ejemplo, puede leerse el trabajo de collage fotográfico o la ironía frente a la práctica militante de organizaciones de derechos humanos como H.I.J.O.S que Mariana Eva Pérez hace en Diario de una princesa montonera (2012); de este modo hay que entender también la película de Albertina Carri, Los rubios (2003), que disuelve las fronteras entre la ficción y la realidad por medio de la inclusión de videoclips, la triplicación de Carri como dramaturga, directora y actriz, y el metadiscurso 
para la crítica al relato mimético por medio de la puesta en escena de la lectura de la negativa a la solicitud de subsidio para la película. En este sentido, la posmemoria se encuadra en la posmodernidad, de la que toma sus formas de trabajo: fragmentación, polifonía, cita, intertextualidad, reflexividad del discurso, poniendo así en duda la legitimidad de relatos totalizadores de sentido, la búsqueda de la verdad y la objetividad en la representación y en la construcción de la identidad (Quílez Esteve 64). Beatriz Sarlo fue, en cambio, una de las primeras que criticó la pertinencia del neologismo para aplicarlo al relato de la posdictadura. En su ensayo, Tiempo presente: cultura de la memoria y giro subjetivo (2005), discute la necesidad de acuñar un nuevo concepto cuando el término no describe, según la crítica argentina, una nueva realidad. Lo que autores como Hirsch o Young creen distintivo de la memoria de la segunda generación no es más que la característica propia de toda narración del pasado (Sarlo 129-130). Así, el prefijo "post" sería redundante, ya que casi todos los recuerdos, incluso los más personales, son mediados $\mathrm{y}$, por lo tanto, el resultado de la comunicación con terceros o la influencia de los medios de comunicación modernos. A su vez, la fragmentariedad no sería específica de la posmemoria, sino propia de las sociedades presentes. En su alegato en contra de la especificidad de la posmemoria, Sarlo concluye que el concepto solo tiene razón de ser en el contexto europeo para referirse a los efectos traumáticos del Holocausto. En cambio, sería infructuoso y equivocado leer con esta herramienta conceptual las producciones artísticas de las nuevas generaciones en otros contextos.

Aunque el concepto ya empieza a usarse para analizar el arte y la narrativa de los hijos de desaparecidos, podría considerarse con Sarlo que no conviene hacer una trasposición acrítica del término. Hirsch piensa en los hijos de los sobrevivientes del Holocausto nacidos en la diáspora que además tienen una relación mediada, especialmente por lo visual, con el pasado en cuestión. En cambio, muchos de los hijos de desaparecidos que desde hace unos años empiezan a reflexionar en sus novelas o películas sobre la experiencia de la dictadura no pertenecen cabalmente a la segunda generación, al menos no en el mismo sentido, ya que vivieron como niños o jóvenes, a veces en carne propia, el terror de las dictaduras, fueron testigos oculares del secuestro de sus padres, apresados con ellos o tuvieron que esconderse o exiliarse. A menudo, y cuando sí llegaron a conocer a sus padres, tienen incluso recuerdos propios o fueron ellos mismos víctimas potenciales (Ciancio 508). Esto es aún más cierto en el caso de los hijos apropiados a quienes se robó su identidad. De modo que la herencia transgeneracional de la memoria y del trauma es en estos casos más compleja, por lo cual habría que distinguir entre: 
los sujetos sometidos a la postmemoria propiamente dicha -los que 'nacieron después' y no llegaron a conocer a sus padres-y aquellos (...) [quienes] vivieron de niños los hechos traumáticos en carne propia, aunque sin comprender, debido a la edad que tenían, el alcance verdadero de los acontecimientos, que sin embargo atraviesan la memoria almacenada en sus propios cuerpos (Logie y Willem 4).

Susan Rubin Suleiman propone hablar entonces, siempre refiriéndose a los niños sobrevivientes de la Shoa, de la "generación 1.5" (cit. por Logie y Willen 4), lo cual podría emparentarse, al menos en los casos de aquellos que fueron secuestrados con sus padres o vivieron la cotidianeidad de una "casa operativa", con la experiencia del trauma de los hijos de desaparecidos. Para comprender la elaboración del trauma en hijos de desaparecidos, las psicoterapeutas Diana Kordon y Lucila Edelman tienen en cuenta los silencios, la paradoja de la presencia y ausencia de los padres desaparecidos, así como un movimiento pendular entre la identificación narcisista y la puesta en duda del amor de sus padres (Kordon y Edelman 1-3).

\section{EL TRAUMA COLECTIVO O CULTURAL. NUEVAS TENDENCIAS}

Incipiente en el ámbito de los estudios de memoria, y estrechamente relacionado con la problemática de la memoria transgeneracional, es el enfoque teórico de los afectos y de la afectividad para comprender los efectos de las violencias históricas sobre las personas. Cuando se trata de la transmisión del trauma de los militantes y víctimas de la represión dictatorial a sus hijos o del trauma en los hijos de desaparecidos durante las dictaduras de los años 70 en los países del Cono Sur, un enfoque de este tipo podría echar luz acerca de las formas ambiguas que cobra la memoria (Gallardo y Saban 1). La reluctancia que existe en algunos sectores de las sociedades argentina y chilena, por ejemplo, para abordar el tema de los afectos asociados a la pérdida de los padres, en el caso de los hijos de desaparecidos, o de las secuelas individuales y familiares de la violencia, en el caso de los hijos de sobrevivientes, se relaciona con una serie de problemas de diversa índole. Por un lado, con el temor de que se pueda banalizar la experiencia revolucionaria de $\operatorname{los} 70 \mathrm{y}$, como consecuencia, mitigar la envergadura violenta de los acontecimientos históricos a manos del terrorismo de Estado. Por otro lado, hace serie con los tópicos de la fidelidad o la traición, el silencio y el prejuicio moral con que aparentemente cargarían las nuevas generaciones. 
Dominique LaCapra fue uno de los primeros autores que investigaron la dimensión social y colectiva del trauma, pero es Angela Kühner quien elabora teórica y críticamente hasta qué punto el estudio de los traumas individuales es también relevante como parte del estudio de una "historia traumática común" (24) con el fin de estudiar tanto la presencia de "traumas en las memorias colectivas" (25) y, al revés, las influencias sociales en los traumas individuales. En este sentido es que Jeffrey Alexander (2004) introduce el término de "trauma cultural" con el que estudia una serie de casos en los que "los miembros de una colectividad sienten que han sufrido un acontecimiento terrible que deja huellas indelebles en la conciencia del grupo" (Alexander 1). En el caso de la memoria de las dictaduras del Cono Sur puede argüirse, con Alexander, que el trauma es no solo un hecho histórico preciso, sino sobre todo una construcción social que se renueva en el tiempo. Este fue el punto de partida también de los derechos humanos en la postdictadura tanto a nivel nacional como continental como fuerza de discurso colectiva (Jelin 37) y lo sigue siendo en el presente; discurso según el cual el trauma no se agota en las heridas reales infligidas al cuerpo social con las desapariciones forzadas de una generación entera, sino que consiste, sobre todo, en las atribuciones que son siempre consecuencia del funcionamiento de las distintas estructuras de poder y de la reflexividad y habilidad discursiva de los distintos actores sociales.

Desde comienzos del siglo veintiuno pueden identificarse algunas nuevas tendencias en los estudios sobre el trauma. Entre las líneas más relevantes se cuentan la de considerar al trauma como un fenómeno plural y global, y ya no solo desde una perspectiva eurocéntrica mayormente construida en torno a la experiencia del Holocausto (Buelens, Durrant et al. 2014; Rothberg 2009; Silverman 2013; Craps 2013), o la posibilidad de considerar, como se dijo antes, la "transmisión transgeneracional del trauma" (Straub y Grünberg 7-38 y Hardtmann 39-56), una teoría según la cual las vivencias traumáticas de los sobrevivientes del Holocausto excederían al sujeto sufriente y se heredarían a través de las prácticas sociales continuando al menos hasta la segunda y acaso la tercera generación. En el contexto sudamericano, como ya fue explicado anteriormente, parece más productivo referir al trauma de los hijos de desaparecidos haciendo uso de otras herramientas teóricas, ya que hay sentimientos de resentimiento o al menos cierto "reclamo" puesto en juego (Reati 2). 
Más recientemente, existe una subtrama en estos estudios que propone escindir el concepto de trauma de la carga de valor y moralidad con la que se lo venía tratando, para tomar en consideración también el diagnóstico de los victimarios y sus descendientes (Fassin y Rechtman 2009), sin que ello implique homologar el trauma de unos y otros (LaCapra 79). Según menciona Stef Craps (2013), desde la filosofía (Hannah Arendt), la historia (Daniel Goldhagen, Christopher Brownings) y la sociología (Harald Welzer) se habían hecho avances para comprender la psicología del victimario y sus móviles de acción, mientras que los estudios culturales y literarios han sido hasta hace poco más bien reacios a aplicar la noción de trauma en estos casos, aunque recientemente empiezan a poner el foco en este tema (Giesen y Schneider 2004). En el caso de los estudios de memoria latinoamericanos no identificamos todavía este tipo de relato memorialístico basado en la perspectiva de los represores y torturadores de las dictaduras del Cono Sur. Hay en cambio desde los años 90 y más específicamente asociados al surgimiento de las segundas generaciones, es decir de los hijos de desaparecidos, discursos que rescatan la memoria de los movimientos armados revolucionarios de los 60 y 70, ya no en forma utópica sino esencialmente en forma crítica, conformando lo que Vezzeti llama la "memoria justa" (17). Por último, habría que señalar el creciente interés que está teniendo el concepto de "resiliencia", no solo en los estudios culturales europeos sino también latinoamericanos, con el cual se estudian, en las representaciones literarias y culturales contemporáneas, no los mecanismos y efectos del trauma sino modos alternativos de respuesta a pasados violentos y estrategias narrativas para visibilizar la vulnerabilidad y contrarrestar los efectos de las catástrofes (por ejemplo, el proyecto "Narrativas de la resiliencia" de Ana M. Fraile Marcos en la Universidad de Salamanca). Desde nuestro punto de vista, esta sería una manera propicia para analizar gran parte de la producción novelística y fílmica que en las últimas décadas se viene publicando o realizando en América del Sur, que podría leerse como un fenómeno opuesto o reactivo a las secuelas del trauma histórico. Aparentemente, la trama ficcional ofrecería un espacio metafórico propicio para narrar de forma más valiente o menos renuente los diversos afectos comprometidos en el proceso de la memoria (Saban, Imaginar el pasado 175-181); afectos que no solo se reducen a las experiencias del dolor y el trauma, sino que tienen que ver con la capacidad de los sujetos para ir más allá del rol de víctimas, poniendo en juego también respuestas positivas, asociadas a la acción. 


\section{BIBLIOGRAFÍA}

Achugar, Hugo. "Historias paralelas / Ejemplares: La historia y la voz del otro". Revista de Crítica Literaria Latinoamericana 18/36 (1992): 51-73.

Alexander, Jeffrey et al. Cultural Trauma and Collective Identity. Berkeley: Univ. of California Press, 2004.

Assmann, Aleida. Erinnerungsräume. Formen und Wandlungen des kulturellen Gedächtnisses. München: Beck, 1999.

Das neue Unbehagen an der Erinnerungskultur. Eine Intervention. München: Beck, 2013.

Formen des Vergessens. Göttingen: Wallstein, 2016.

Assmann, Jan. Das kulturelle Gedächtnis. Schrift, Erinnerung und politische Identität in frühen Hochkulturen. München: Beck, 1992.

Religión y memoria cultural. Trad. Marcelo Burello y Karen Saban. Buenos Aires: Lilmod, 2008.

Baer, Alejandro y Natan Sznaider. The memory and forgetting in the post-holocaust era: the ethics of never again. London/New York: Routledge, 2017.

Benjamin, Walter. "Über den Begriff der Geschichte". Iluminationen. Frankfurt am Main: Suhrkamp, 1980. 251-261.

Buelens, Gert et al., comp. The Future of Trauma Theory. Contemporary Literary and Cultural Criticism. New York: Routledge, 2014.

Carri, Albertina, dir. Los rubios, 2003. Película.

Ciancio, María Belén. “¿Cómo (no) hacer cosas con imágenes? Sobre el concepto de postmemoria”. Constelaciones. Revista de Teoría crítica 7 (2015): 503-515.

Clifford, James. "Diasporas”, Cultural Anthropology 9/3 (1994): 302-338.

Craps, Stef. Postcolonial Witnessing Trauma Out of Bounds. London: Palgrave Macmillan UK, 2013.

Cruz Suárez, Juan Carlos. "Literatura y memoria RAM. Apuntes para un estudio de la memoria social en un marco global". Hans Lauge Hansen et al., comp. La memoria novelada. Memoria transnacional y anhelos de justicia. Bern: Peter Lang, 2015. 183-222.

Eco, Umberto. “An Ars oblivionalis? Forget it”, Modern Language Association 103 (1988): 254-261.

Erll, Astrid. Kollektives Gedächtnis und Erinnerungskulturen. Eine Einführung. Stuttgart: Metzler, 2011.

Fassin, Didier y Richard Rechtman. The Empire of trauma. An Inquiry into the Condition of Victimhood. Trad. R. Gomme. NJ/Oxford, Princeton UP, 2009.

Feierstein, Daniel. El genocidio como práctica social. Entre el nazismo y la experiencia argentina. Buenos Aires: Fondo de Cultura Económica, 2008.

Ferrandíz, Francisco. El pasado bajo tierra. Exhumaciones contemporáneas de la Guerra Civil (Memoria Rota. Exilios y Heterodoxias). Madrid: Anthropos, 2014.

Gallardo, Milena y Karen Saban. "Búsquedas estéticas para el afecto y la desafección. La memoria de hijos de sobrevivientes y desaparecidos en Chile y Argentina". Revista Vanderbilt e-Journal of Luso-Hispanic Studies. Genschow, Karen y Katarzyna Moszczyńska-Dürst, 
comp. Dossier "Ficciones hispánicas y latinoamericanas del s. XXI desde del poder y las emociones". (Publicación 2020).

Gatti, Gabriel. El detenido-desaparecido. Narrativas posibles para una catástrofe de la identidad. Montevideo: Trilce, 2008.

Giesen, Bernhard y Christoph Schneider (eds.). Tätertrauma: Nationale Erinnerungen im öffentlichen Diskurs. Konstanz: UVK Verlagsgesellschaft, 2004.

Hansen, Hans Lauge. "Formas globales e historias locales. Influencias transnacionales en la narrativa actual sobre la guerra civil". Hans Lauge Hansen et al., comp. La memoria novelada. Memoria transnacional y anhelos de justicia. Bern: Peter Lang, 2015. 123-150.

Halbwachs, Maurice. La memoria colectiva. Trad. Federico Balcarce. Buenos Aires: Miño Dávila, 2010.

Los marcos sociales de la memoria. Trad. M. A. Baeza y M. Mujica. Barcelona: Anthropos, 2004.

Hardtmann, Gertrud. "Lebensgeschichte und Identität. Die zweite Generation - Opfer und Täter”. Kurt Grünberg, comp. Unverlierbare Zeit. Psychosoziale Spätfolgen des Nationalsozialismus bei Nachkommen von Opfern und Tätern. Tübingen: Diskord, 2001. 39-56.

Hirsch, Marianne. The generation of Postmemory: Writing and visual culture after The Holocaust. New York: Columbia Univ. Press, 2012.

Huyssen, Andreas. Present pasts. Urban palimpsests and the politics of memory. Stanford: Stanford U.P., 2003.

Twilight Memories. Marking Time in a Culture of Amnesia. London/New York: Routledge, 1995.

Jelin, Elizabeth. Los trabajos de la memoria. Madrid: Siglo XXI de España Editores, 2002.

Jureit, Ulrike y Christian Schneider. Gefühlte Opfer. Illusionen der Vergangenheitsbewältigung. Stuttgart: Klett-Cotta, 2011.

Kordon, Diana y Lucila Edelman. "Hijos, a secas. Efectos multigeneracionales de la represión”. Página 12. 18 de noviembre de 2004. https://www.pagina12.com.ar/diario/ psicologia/9-43783-2004-11-19.html

Kühner, Angela. Trauma und kollektives Gedächtnis. Gießen: Psychosozial-Verlag, 2008.

LaCapra, Dominique. Writing History, writing trauma. Baltimore/London: John Hopkings UP, 2001.

Lachman, Renate. Gedächtnis und Literatur: Intertextualität in der Moderne. Frankfurt am Main: Suhrkamp, 1990.

Levy, Daniel y Natan Sznaider. The Holocaust and memory in the global age. Trad. Assenka Oksiloff. Philadelphia: Temple University Press, 2006.

Lie, Nadia y Kirsten Mahlke. "Transnational Memory in the Hispanic World: Preface". European Review 22/4 (2014): 543-545.

Logie, Ilse y Bieke Willem. "Narrativas de la postmemoria en Argentina y Chile: la casa revisitada". Alternativas 5 (2015): 1-25.

Mandolessi, Silvana y Mariana Eva Pérez. "The Disappeared as a Transnational Figure or How to Deal with the Vain Yesterday". European Review 22/4 (2014): 603-612.

y Maximiliano Alonso, comp. Estudios sobre memoria. Perspectivas actuales y nuevos escenarios. Córdoba: Editorial Universitaria Villa María, 2015. 
Meier, Christian. Das Gebot zu Vergessen und die Unabweisbarkeit des Erinnerns. Vom öffentlichen Umgang mit schlimmer Vergangenheit. München: Siedler, 2010.

Nietzsche, Friedrich. "Vom Nutzen und Nachteil der Historie für das Leben". Ed. Karl Schlechta. Friedrich Nietzsche Werke. 1874. Berlin: Carl Hansen Verlag, 2000.

Nora, Pierre. Zwischen Geschichte und Gedächtnis. Berlin: Wagenbach, 1990.

Oberti, Alejandra. "Potencia y Acción: el testimonio en América Latina", Amovi. Archivo de memoria oral de las víctimas 6 (2015): 479-499.

Pérez, Mariana Eva. Diario de una princesa montonera $-110 \%$ verdad-. Buenos Aires: Capital intelectual, 2012.

Quílez Esteve, Laia. "Hacia una teoría de la posmemoria. Reflexiones en torno a las representaciones de la memoria generacional". Historiografias 8 (2014): 57-75.

Reati, Fernando. "Entre el amor y el reclamo. La literatura de los hijos de militantes en la posdictadura argentina". Alternativas. Revista de estudios culturales latinoamericanos 5 (2015): 1-45.

Ricoeur, Paul. La memoria del tiempo pasado. Memoria y olvido. Trad. Gabriel Aranzueque. Madrid: Arrecife, 1999.

Rothberg, Michael. Multidirectional memory: remembering the Holocaust in the age of decolonization. Stanford: Stanford Univ. Press, 2009.

Saban, Karen. Imaginar el pasado. Nuevas ficciones de la memoria de la última dictadura militar argentina (1976-1983). Heidelberg: Winter Verlag, 2013.

reseña de Das Gebot zu vergessen und die Unabweisbarkeit des Erinnerns. Vom öffentlichen Umgang mit schlimmer Vergangenheit, de Christian Meier. Revista de Estudios de Genocidio 6 (2011): 99-103.

Sarlo, Beatriz. Tiempo pasado. Cultura de la memoria y giro subjetivo. Una discusión. Buenos Aires: Siglo XXI, 2005.

Silverman, Max. Palimpsestic Memory. The Holocaust and Colonialism in French and Francophone Fiction and Film. New York: Berghahn Books, 2013.

Straub, Jürgen y Kurt Grünberg. "Die Gegenwart der Vergangenheit. Vorbemerkungen zur unverlierbaren Zeit”. Kurt Grünberg, comp. Unverlierbare Zeit. Psychosoziale Spätfolgen des Nationalsozialismus bei Nachkommen von Opfern und Tätern. Tübingen: Diskord, 2001: 7-38.

Todorov, Tzvetan. Los abusos de la memoria. Barcelona: Paidós, 2000.

Vezzeti, Hugo. Sobre la violencia revolucionaria. Memorias y olvidos. Buenos Aires: 2009.

Wajcman, Gérard. L'objet du siècle. Paris: Verdier, 1998.

Weinrich, Harald. Gibt es eine Kunst des Vergessens? Basel: Schwabe \& Co., 1996.

Welzer, Harald et al. "Opa war kein Nazi”: Nationalsozialismus und Holocaust im Familiengedächtnis. Frankfurt am Main: Fischer-Taschenbuch Verlag, 2002.

y Dana Giesecke. Das Menschenmögliche. Zur Renovierung der deutschen Erinnerungskultur. Hamburg: Körber-Stiftung, 2012.

Young, James Edward. At memory's Edge: after-images of the Holocaust in contemporary art and architecture. New Haven: Yale Univ. Press, 2000. 